\title{
Traditional and Skilled Birth Attendants in Zimbabwe: A Situational Analysis and Some Policy Considerations
}

\author{
Naume Zorodzai Choguya \\ Department of Anthropology and Sociology, University of the Western Cape, Private Bag X17, Bellville 7535, South Africa \\ Correspondence should be addressed to Naume Zorodzai Choguya; zchoguya@gmail.com
}

Received 9 March 2015; Accepted 15 April 2015

Academic Editor: Kaushik Bose

Copyright ( 2015 Naume Zorodzai Choguya. This is an open access article distributed under the Creative Commons Attribution License, which permits unrestricted use, distribution, and reproduction in any medium, provided the original work is properly cited.

\begin{abstract}
The paper focuses on the situational analysis of traditional birth attendants (TBAs) and skilled birth attendants (SBAs) in Zimbabwe. Against a background of a frail health care system, characterised by a shortage in skilled professionals, increased cost of medical care, and geographic and economic inaccessibility of health care centres among others, TBAs have remained a life-line for especially many rural women in maternal health care provision. Moreover, TBAs have also found their way into the urban areas of Zimbabwe. The shift in international policy and health funding toward skilled birth attendants (i.e., an accredited health professional) has materialized into concerted government efforts to increase numbers of both midwifery training institutions and midwives themselves. The call for SBAs, though a worthy ideal, is out of touch with the lived realities of pregnant women in low resource settings such as Zimbabwe. The study is concerned with situational analysis of TBAs and SBAs in maternal health care service provision in Zimbabwe analysing and evaluating policy considerations.
\end{abstract}

\section{Introduction}

Methodologically, this paper is based on desk research which entailed extensive sourcing and reading of literature related to maternal health issues in Zimbabwe. The paper utilizes a literature review which concentrated on literature related to the following topics.

(i) Zimbabwean women's experience and perspectives of access to maternal health services.

(ii) Implications of current health system characteristics for access to maternal health services.

(iii) Specific role of Traditional Births Attendants (TBAs) (Zimbabwe and elsewhere) and other key actors at community level.

Using the above criteria, articles and reports were reviewed which included peer reviewed publications, organisational reports, case studies, and other sources of information including media reports coming with a comprehensive picture on the current state of affairs regarding maternal health service provision and the related challenges.
For many women living in the global south, antenatal care and institutional deliveries attended by skilled health workers remain a distant reality. Therein women's "choices" and or "preference" for home births are heavily influenced by both micro- and macrofactors including cultural norms, religious beliefs, cost, and accessibility of the services. Moreover, TBAs speak the local language, have the trust of community members, and can provide psychosocial support at birth; thus, they are an integral part of birth related services [1]. Many countries often have a shortage of trained medical professionals and maternal health care is consequently provided by TBAs $[2,3]$. Hansson [4] observed that maternal and child health care in Zimbabwe is provided by traditional, modern scientific, and church controlled medical services.

Globally, TBAs have been invaluable in maternal health and well-being of pregnant women and in managing birthing, especially in the rural areas of developing countries. The term TBA refers to traditional, independent (of the health system) community-based health providers. These include trained and untrained TBAs. Trained TBAs are those who have received a short course of training through the modern health care sector to upgrade their skills and can be in 
possession of a badge or certificate which has been issued on completion of the training. Untrained TBAs are those that acquired their skills informally through understudying and assisting other TBAs. This is done until such a time when the mentee can offer similar services on their own unsupervised. However, TBAs are not a homogenous group and their profile varies considerably across time, space, and social settings. Whilst the defined category of a TBA might be difficult to apply in general, there are some universally acknowledged attributes [5]. Furthermore, the concept of "traditional birth attendant" itself is also seen as an artificial construct made by the biomedical system [6], to accommodate the system into international health development policies with a focus on delivery care $[7,8]$. During the 1980s, the term "traditional midwife," was used which expresses the broad work field of a TBA in assisting women during pregnancy, when they give birth, and during postpartum period [9]. Until the mid-90s, the term "trained" attendant was commonly used and it included both professional and nonformally trained community-based providers of care during pregnancy, childbirth, and postnatal period [10]. From 1996 onwards however, the term "skilled" attendant (SBA) was employed which refers exclusively to people with midwifery skills (e.g., doctors, midwives, and nurses) who have been trained to be proficient in the skills necessary to manage normal deliveries and diagnose, manage, or refer complications.

TBAs have traditionally been assisting women during childbirth, providing local women with delivery and pregnancy monitoring services, and giving them and their babies care after childbirth. The official government position and policy regarding TBAs in the country have been wavering in the past decade. Immediate postindependent Zimbabwean government recognized TBA practice and valued TBAs services and contributions to maternal and child health. The launch of the safe motherhood program, in 1983, witnessed an estimated 15000 TBAs trained to improve maternal health outcomes [11]. However, current global policy shifts towards skilled attendance and institutional delivery has been accepted in Zimbabwe. Institutional delivery entails delivering a baby in a medical facility, under the supervision of a skilled medical professional. This is supposed to reduce instances of maternal and neonatal mortality. The WHO [12] posits that skilled birth attendance during delivery is a key strategy in the reduction of maternal deaths and defines a skilled attendant as

an accredited health professional-such as a midwife, doctor, or nurse-who has been educated and trained to be proficient in the skills needed to manage normal (uncomplicated) pregnancies, childbirth, and the immediate postnatal period and in the identification, management, and referral of complications in women and newborns [13].

The efforts to ensure skilled births attendance have taken many forms across time and space. Thus, there is no single model that has been used to increase skilled attendance internationally. However, $[14,15]$ argue that an ideal strategy does exist. This strategy employs health workers with midwifery skills-preferably midwives and nurse-midwiveswho possess the ability to facilitate normal births at a basic health facility, to recognize and manage certain obstetric complications, and to refer women to a more comprehensive care center in the event of an obstetric emergency. In Zimbabwe, however, government intentions are somewhat confusing. For instance, calls for a return to the village health worker model of the past were once made, as well as the reorientation of TBAs to mobilize for improved skilled attendance at delivery. At the same time, the need to train health service providers with emergency obstetric and neonatal care skills is emphasised. According to newspaper and UNICEF reports over the past two years, midwifery training in Zimbabwe has been scaled up. In this regard, it was reported that three training schools for midwifery would be opened to lessen the shortage in skilled staff, to reduce maternal and mortality rates, and to improve maternal health. According to a report by a government official, skilled attendance at delivery had declined to $68 \%$ in the last decade and home deliveries were at about $28 \%$. One reason for this is the exodus of trained midwives from the formal health care services ${ }^{1}$. Another report by UNICEF [16] indicated that 1904 new midwives had been trained in the country in an effort to reduce high maternal deaths. The 21 midwifery training schools in the country had been upgraded and refurbished and efforts were made to enroll more students in midwifery. It is hoped that the health sector will begin to recover after a decade-long decline $e^{2}$.

\section{A Situational Analysis of the Zimbabwean Context}

Zimbabwe is a multiethnic country in Southern Africa whose population on 18 August 2012 was 12973808 of which 6234931 were males and 6738877 were females. This means that the overall sex ratio was 93 males: 100 females [19]. In Zimbabwe, vast social and geographical disparities exist in health indicators and health services [20]. Health care is pluralistic: western biomedicine, faith healing, patent medicine shops, and traditional medicine coexist, and careseekers choose among these options to meet their health needs $[21,22]$. Literature shows that births without skilled personnel and without access to life-saving drugs are the commonest practice for millions of mothers in the poorest countries where mortality rates and morbidity of the mothers are the highest $[23,24]$. Moreover, 7-10 million women and girls over the world suffer from severe or long lasting illnesses caused by pregnancy and childbirth complications [24]. The use of unskilled personnel (including TBAs) is argued to be among the reasons for the high maternal and infant mortality rates in SSA in general and in Zimbabwe in particular. In Zimbabwe, at least ten women die every day of pregnancyrelated complications [25]. However, despite the expansion of interventions, including construction of more health facilities close to the community and increased use of antenatal clinic [26], home deliveries attended by TBAs have persisted. In Zimbabwe, maternal and perinatal mortality constitute a significant burden of disease and there is underutilization of 
prenatal care (PNC) services and this is argued to affect both the health of the mother and the child. This underutilization of formal health institutions has been attributed to the use of alternative medicine. Furthermore, inadequate and unavailable health care services as well as people's rootedness in traditional practices leave the utilization of TBAs the preferred and viable option for many.

Historically, indigenous practices constituted the major source of survival in Africa, and the care of pregnant women was at the centre of these practices. In Zimbabwe, the field of maternal health care has been entrusted to TBAs who are part of the Zimbabwe Traditional Healers Association (ZINATHA) and whose midwifery roles range from taking care of pregnancy and childbirth to treating infertility and to playing an advisory role in family matters $[4,27]$. Usually, the role of TBAs on reproductive health starts immediately after a woman conceives pregnancy. They are consulted for any health problem occurring among pregnant women until after delivery and have rich knowledge of traditional medicine used in managing pregnancy and child delivery. Additionally, TBAs educate pregnant women on appropriate diet to take, pregnancy-related taboos, and on how to take care of infants after birth and they are known to have some knowledge of risk signs during pregnancy. Furthermore, TBAs are also responsible for management of family planning, getting opposite sex for a woman who was giving births of one sex, managing some temporal impotence and infertility using traditional remedies. Some of TBAs are also involved in girls' initiation to adulthood in some ethnic groups [28-30]. Above all, TBAs are primarily involved in child deliveries.

MMEIG [31] highlights that maternal mortality worsened by $28 \%$ from 1990 to 2010 and Zimbabwe is ranked among the 40 countries in the world with high MMR of over 960 maternal deaths per 100000 live births. Moreover, the primary health care assessment of 2009 revealed that less than $50 \%$ of the sampled households were satisfied with the performance of the health system. By inference, this propels people to consider other options with regard to maternal health which may mean utilizing the "tried and tested" TBAs. Though there has been an increase in women attending at least one antenatal care visit from $81 \%$ in 1999 to $94 \%$ in 2006 (ZDHS) and 93\% in 2009 (Multiple Indicator Monitoring Survey (MIMS)), more than $30 \%$ of deliveries take place outside the formal system [32, 33]. Despite attending at least one ANC visit, it is clear that women then have their babies outside formal institutions often under the care of TBAs. Given the obvious urban bias in health care provision, the people in the rural areas are isolated from access and are thus most likely to resort to TBAs.

In Zimbabwe, access to quality formal birthing services is quite low, a condition that is blamed for the country's current high maternal mortality figures where at least 10 women die daily due to pregnancy-related factors and a much larger number suffer from short and long term maternalrelated morbidities [26, 34]. Furthermore, Zimbabwe's multifaceted crisis (1999-2008) induced an exodus of significant proportions of primary health care professionals to the extent that the Ministry of Health and Child Welfare (MoHCW) reported that $60 \%$ of physicians' posts were vacant across

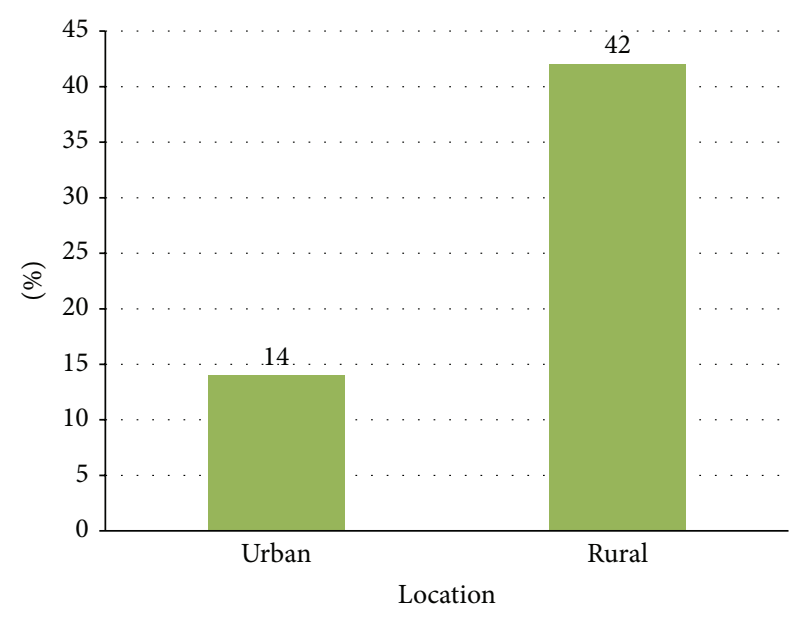

FIGURE 1: Rural-urban distribution of home births. Source: ZDHS, 2011.

the country [35]. This is at the time where, according to WHO [36], only $60-69 \%$ of births are attended by trained health professionals depending on the geographical location. According to TARSC and $\mathrm{MOH}$ [20], 52\% of women gave birth under the supervision of skilled attendants compared to 68 and 7\% in 2007 [37] and 73\% in 1999 [34]. Home births are predominant in rural areas more than in urban areas. Figure 1 illustrates the distribution of home births in Zimbabwe by geographical location.

Since independence, the Ministry of Health policies and programs show the government's efforts to improve delivery care and to reduce maternal deaths. The National Reproductive Health policy, the National Health Strategy 20092013, and the Zimbabwe National Maternal and Neonatal Health Road Map 2007-2015 are testimony to these efforts. Nevertheless, the prevalence of home births has remained high. In rural areas, women, especially the poor ones, depend more on TBAs for assistance during delivery. Moreover, most of the trained midwives are based in urban areas. Thus, the percentage of home births is also considerably higher in rural areas compared to urban areas of Zimbabwe. In addition, the problem of unavailability of healthcare personnel and infrastructure is worse in rural and remote areas of Zimbabwe $[20,21]$. A situational analysis study established that $28.8 \%$ of women delivered at home, $1.7 \%$ at the TBA's home, and $0.3 \%$ at a Faith healer's home [37]. The proportion of home deliveries without a skilled birth attendant stood at 69 percent in 2009 [38]. According to Global Observatory [36] skilled attendance at delivery dropped from $73 \%$ in 1999 to $60 \%$ in 2009 and maternal mortality increased from 390/100 000 births in 1990 to 790/100 000 in 2008 and is currently pegged at $960 / 100000$ [25]. Despite the government efforts, there is little evidence and likelihood that this situation will improve soon.

The 1980s showed a general improvement in most of the major health indicators and service utilization, attributable to the expansion and improvements in the area of primary health care. Nonetheless, signs of deterioration were evident in the 1990s. By the year 2000, Zimbabwe's well-organized 


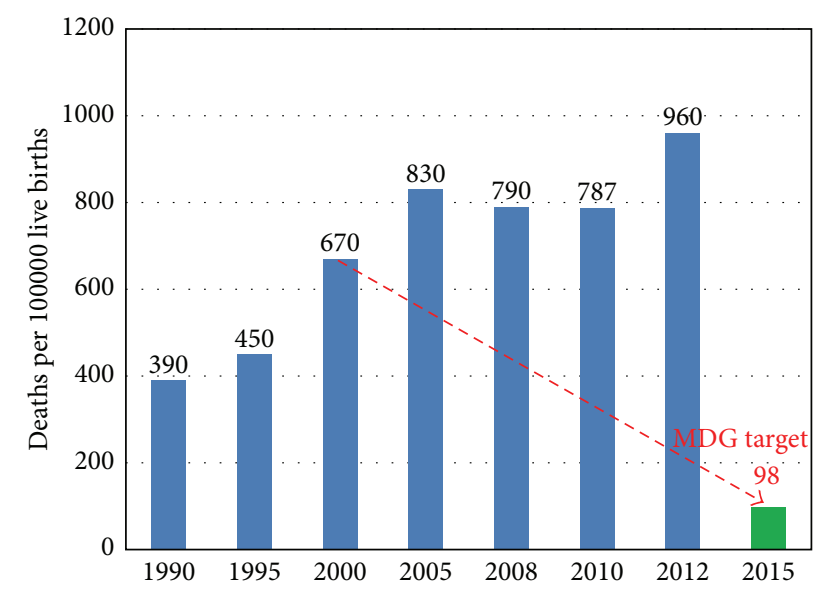

FIgURE 2: Maternal mortality trend in Zimbabwe. Source: WORLD BANK 2011 [17], 2013, GONDA. 2012 [18].

public service delivery system fell into steady decline toward near collapse in 2008. The trends were a reversal of the gains made in the previous decade. For example, maternal mortality increased dramatically from 283 per 100000 live births in 1990 to 390 per 100000 births in 1994, to 578 in 1999 , to 830 in 2005/6, and to 790 in 2008. Currently, the maternal mortality ratio estimates from the 2010/2011 Zimbabwe Demographic Health Survey are 960 per 100000 births, one of the highest in the world (World Bank, 2013). This rise in MMR is against the backdrop of government commitment and intention to reduce MMR by three quarters (to 98 deaths/100 000 live births) by 2015 (see Figure 2).

A recurrent issue in maternal research and policy literature relates to the (in)ability of TBAs to deliver safe pregnancy and childbirth services. Hotly debated is the TBAs knowledge or lack of it; how they acquired the knowledge and skills they draw on in their practice. Concerns are compounded by the well documented low literacy levels of TBAs. Even against the background of TBA training, concerns still abound arguing on the efficacy of the training. For example, Maimbolwa [39] notes that a traditional midwife (and by inference TBA) with or without training is not recognized as "skilled." However, TBAs are especially important services providers in rural areas because of the urban bias in health service provision that leave the more geographically inaccessible rural areas on the margins of healthcare provisions. Furthermore, most rural health centres either are understaffed or lack the necessary deliverables or both. Thus, deliveries in most rural areas are assisted by either trained or untrained TBAs or family members [40]. This is against the background of the majority of Zimbabweans living in the rural areas [41]. Although approximately two-thirds of Zimbabweans live in rural communities, there is a clear urban bias in the distribution of public sector health workers. Rural areas suffer from vacancy rates of 60 percent for both physicians and nursing positions, compared to 20 percent for physicians and 43 percent for nurses in urban areas. However, urban health facilities still suffer from significant service delays as health worker supply continues to fall short of service demand
[42]. However, even if all established MoHCW positions for doctors, nurses, and midwives were filled in Zimbabwe, health care worker density would still be only 1.65 per 1000 population, well short of the WHO recommendation 2.28 per 1000 population [43].

Reasons for most TBA assisted home deliveries include poverty, distance to health facilities, lack of information, inadequate services and medical supplies, lack of competent personnel in reproductive health at the health facilities, and above all the cultural practices related to birthing [24, 44]. These factors are more likely to contribute to women preferences to go to TBAs for child delivery than to formal health facilities. The role of traditional birth attendants in provision of health care in resource poor countries is still important because of the current inadequacy of human resource for health. TBAs will thus remain the main providers of child deliveries in most rural areas for years to come. The reduction of maternal and newborn mortality in such contexts requires rigorous efforts by governments and nongovernmental organizations in identifying, recruiting, and training TBAs.

\section{Paradigm Shift to Skilled Birth Attendants}

The 1970s witnessed international organizations, including the WHO, actively promoting community-based care, including antenatal care (screening of "at risk" women), the training of TBAs, and the establishment of referral mechanisms to deal with pregnancy and childbirth complications. The result was intensive investments by governments, donors, and nongovernmental organizations (NGOs) in the training of TBAs even in Zimbabwe. Unfortunately, little attention was paid to a systematic analysis and evaluation of the effects of TBA training programmes on maternal and newborn health outcomes. Since there was arguably no significant improvement in maternal mortality after two decades, the international safe motherhood partners withdrew support for further training and investments in TBAs. The 1990s thus witnessed a global policy shift towards SBAs and institutional delivery. By 1997, international attention had shifted to emphasize "skilled birth attendance." Currently, efforts are being made over the world, including in Zimbabwe, to invest in the training and deployment of skilled birth attendants. Despite the paradigm shift to SBAs in the late 1990s, some countries have continued to invest in TBAs, with varying results. The Cochrane Review [45] concluded that "after more than three decades of experience, the evidence to support TBA training has been limited and conflicting."

This shift in policy towards SBAs has had the effect of marginalizing TBA practice in maternal health care provision in Zimbabwe. Nonetheless, researchers have expressed concern that this shift in policy took place without adequate evidence on the relevance and effectiveness of the TBA training initiatives or the services provided by the TBAs themselves [46, 47]. Researchers have pointed out that TBAs will continue to exist, to practice their skills, and to be sought out by pregnant and birthing women despite policy changes $[48,49]$. Zimbabwe's case is further complicated by its underperforming health care system. The post- 2000 


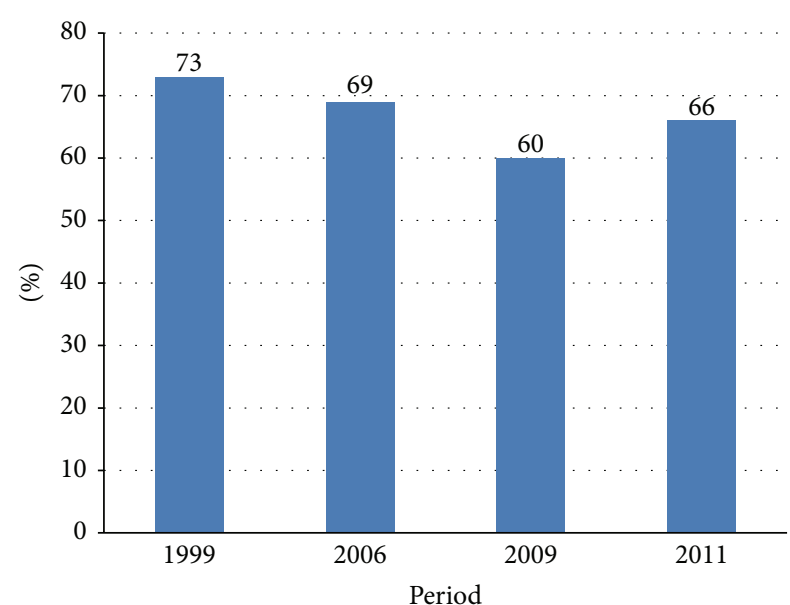

FIGURE 3: Skilled attendance at birth in Zimbabwe. Source: ZDHS, 2011.

crisis in Zimbabwe has been characterized by inadequate and/or unavailable health care services. This combined with people's rootedness in cultural practices leaves the utilization of TBAs the preferred and viable option for many. Given the prevailing conditions in Zimbabwe, TBAs remain the viable first responders in the hierarchy of maternal health care and their services are still required by women especially in rural areas where issues of access availability and affordability predispose them to deliver at home. Severe shortages of skilled attendants are common in the developing world. As a general target, at least one skilled attendant for every 200 births per year is recommended, but some developing countries have only one skilled attendant per 15,000 births. Shortages are especially severe in rural areas, since health professionals are often concentrated in cities. WHO estimates that the number of skilled attendants in the developing countries needs to be increased by at least 333, 000 [50]. For a mother and her newborn, a skilled birth attendant can make the difference between life and death [51].

\section{The Future of Maternal Health in Zimbabwe: Key Insights and Policy Considerations}

The ZDHS [34] results also showed a decline from $73 \%$ in 1999 to $69 \%$ in 2006 and a further decline to $60 \%$ in 2009 [52] in skilled attendance at delivery (see Figure 3).

Gupta and Dal Poz [53] found that 41 percent of physicians, 7 percent of nurses, and 10 percent of midwives reported dual employment, highlighting the health system's inability to satisfactorily compensate its more highly trained staff. This has repercussions for quality and service availability and quality within the public sector as health workers may sacrifice their public service obligations for the greater financial incentives of the private sector. This therefore means that the understaffing of health institutions will be a perennial feature in the country's healthcare system. All these factors combined paint a gloomy picture of maternal health.

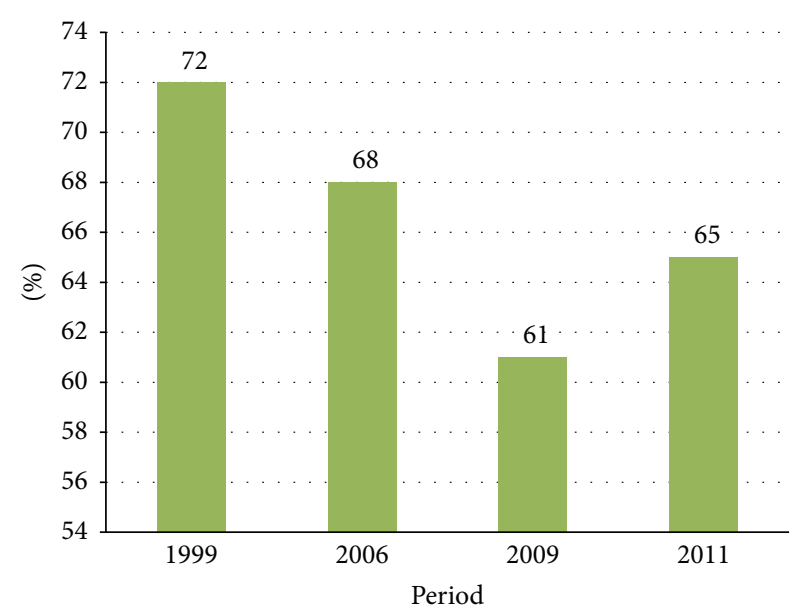

FIGURE 4: Institutional deliveries in Zimbabwe. Source: ZDHS, 2011.

Institutional deliveries also declined from $72 \%$ in 1999 to $68 \%$ in 2006 [34] and in 2009 MIMS reported a 7\% decline to $61 \%$, as graphically illustrated (Figure 4 ).

In 2009, the Ministry of Health and Child Welfare of Zimbabwe highlighted that there was an increase in the underutilization of the health care system-especially the public health sector, which is supposedly the major supplier of health care [54]. Chimhete [55] reported that many people were being forced to seek traditional care due to high staff turnover, high hospital costs, and shortages of essential drugs at most clinics and hospitals. This shows that people are opting for alternative medicine and care. With reference to pregnancy care, people inevitably resort to TBAs' services. Literature provides three TBAs' explanations regarding the persistence of homebirths: the wide-ranging nature of the TBAs' services, the high quality of their services, and the responsiveness of their services to the sociocultural and economic needs of women. TBAs have reiterated that hospitalbased providers tend to disregard people's cultural beliefs, as well as patients' preferences [21]. Studies have also shown that the nonutilisation of maternity services is associated with poor fetal and maternal outcomes and that the pattern of utilisation of maternity services by rural women was based on rational decision making, which took into account not only the distance to a service but also whether the care provided was seen to be good $[20,56,57]$.

Despite the calls for TBA integration in the formal health system $[58,59]$, TBAs have continued to practice outside the formal health system. In this regard Kruske and Barclay [48] argue that approximately half of all births and as many as $95 \%$ of women in developing countries are attended by TBAs. Thus, they opine that, rather than continuing to develop interventions grounded in a Western biomedical world view of healthcare, there is a need to develop programs that are inclusive of healers who reflect the sociocultural beliefs of the community. They put a call to the needs to understand the local context. This echoes Jordan's [60] calls for the replacement of top-down, culturally inappropriate, biomedically oriented approaches with models of mutual accommodation. 
This is what Graham [61] calls the "partnership paradigm," that is, the mutual cooperation of biomedical and indigenous systems. However, it is at the interface between biomedical (Western) and indigenous systems where problems arise and also lie.

4.1. Policy Provisions for Maternal Health Care and Their Implementation. Poor health status, limited access to high quality intrapartum care, and lack of control over fertility have been cited as contributing factors to maternal mortality in Zimbabwe $[62,63]$. So, what is to be done?

The Ministry of Health and Child Welfare has a policy of free care at clinic level. Like other primary health care services maternity services are meant to be rendered free of charge in all primary health care facilities. However, on the ground people are made to pay for the services and the exemption policy has not been applied uniformly by the local government and mission clinics [64]. This requirement to pay is one factor that propels people to use TBAs as the payments are negotiated, can be in kind, and have flexible payment options.

The return to the village health worker model of the past also seems problematic for the current regime. For example, in 2010, only 19 percent of villages countrywide were estimated to have active village health workers, due to a cessation of the training programme in most districts, as well as poor and uncoordinated remuneration across programmes [41]. In one community survey of 25 districts, less than half of the households reported having a health worker in their wards and the village health workers reported that they were not supplied with basic medicines. This means that in essence the VHW is now also extinct and this means that TBAs become first in line and sometimes the only responder to women's maternal health needs.

4.2. Preventing Avoidable Deaths. First of all, it is important to prevent avoidable maternal health related deaths. This implies a commitment to reestablish and or resuscitate basic social services throughout Zimbabwe, particularly health related ones. The aim is to stop the most obvious and most easily preventable problems from occurring. These include prenatal and early childhood malnutrition as well as preventable early death. Focus should be on primary health care particularly in rural areas. The rural areas were most affected by the crisis [65] and around 70\% of Zimbabweans live in rural areas [66]. Moreover, this is where the biggest challenges in maternal services in terms of both quality and quantity have always been and where poverty is the greatest $[66,67]$. According to UNFPA [10], emergency obstetric and newborn complications are significantly more in rural areas of the country, with Zimbabwe experiencing 166 such complications per day and 103 such per day in the rural areas.

The Medium Term Plan 2011-2015 (MTP) and the Zimbabwe Agenda for Sustainable Socio-Economic Transformation from October 2013 to December 2018 (Zim Asset) are the two most recent policy instruments informing the health care system at present. The Medium Term Plan 2011-2015 (MTP) is the economic blueprint of Zimbabwe which was adopted and approved by Cabinet in 2011. It sets the strategic vision and direction that the economy should take until 2016. With reference to the MTPs blueprint, its argument in favour of primary health care was made in terms of cost savings rather than in terms of the impact on maternal or child health (page 181). Though the MTP did prioritize U5MR, maternal mortality, it also set a number of idealistic "policy targets" such as reducing the under-five mortality rate by almost two-thirds in six years (pages 181-3), something that no country has ever done before. The MTP's health policy targets, such as rehabilitating the health infrastructure to $80 \%$ functionality, are likely more realistic than ZimASSET's emphasis on $100 \%$ provision of medicines and medical supplies to all health units. However, ZimASSET includes a commitment to "providing social services encompassing the construction of hospitals and other social amenities, particularly in the new resettlement areas" (page 34). In terms of priorities, ZimASSET emphasises "basic and comprehensive emergency obstetric care" and an array of measures related to prevention of mother-to-child transmission of HIV... and $90 \%$ of mothers delivering their babies in health facilities (page 67). "Medicines and medical supplies are to be availed from current $45 \%$ to $100 \%$ " (page 68 ) and "all vacant posts filled" (page 71), but gives no details of the how.

Another policy of interest is the Zimbabwe Agenda for Sustainable Socio-Economic Transformation from October 2013 to December 2018. "Zim Asset was crafted to achieve sustainable development and social equity anchored on indigenisation, empowerment, and employment creation which will be largely propelled by the judicious exploitation of the country's abundant human and natural resources" (Foreword, ZimASSET Document). Generally, ZimASSET contains no explicit commitment to concentrate on proven, high impact, cost-effective primary health care measures and it uses the term "primary health care" only once (page 66), without defining it. ZimASSETs' results matrices, rather, concentrate on the construction and rehabilitation of physical infrastructure and on physical inputs to the health system. While the MTP dedicated a separate chapter to health issues, ZimASSET buries health under Social Services and Poverty Reduction, one of its four "clusters or priorities," (pages 910). Only one of ZimASSETs' ten immediate priority actions (called "quick wins") under Social Services and Poverty Reduction Cluster relates to primary health care; ironically, it is one of those parts of primary health care that is the longest and hardest to implement, namely, "access to water and sanitation" (page 63). Neither MTP nor ZimASSET mentions the high rate of unemployment of the recently graduated nurses in Zimbabwe, 2500 in total in late 2012, and neither document lays out a strategy for improving the quality of care in a system where $69 \%$ of the government's budget goes to salaries, leaving little fiscal room for supplies, equipment, or infrastructure [68].

4.3. Building Women's Capabilities. Extreme poverty is perhaps the major challenge on the long run. Even in the postcrisis period of 2011-12, 16.2\% of Zimbabweans lived in extreme poverty; in rural areas, $30.2 \%$ lived in extreme poverty [66]. Although approximately $52 \%$ of the population in Zimbabwe is female, women are disproportionately 
represented in politics and in other decision-making positions. The health system, especially primary health care, is important in promoting and building a healthy nation.

Maternal and infant mortality are high in SSA; however, these women and infants do not need to suffer and die; most lives could be saved using relatively easy and cheap methods [24, 44]. Efforts are being made by the governments in developing countries to reduce maternal deaths, stillbirths, and neonatal deaths related to intrapartum events in unattended births [24]. These include use of antinatal clinic, immunization, and insistence to deliver in health facilities $[24,69,70](\mathrm{MoH}, 2003)$. If TBAs could be taken on board after training, they could be instrumental in averting some of these health problems especially maternal and newborn mortality. Interventions to reduce adverse outcomes in births attended by TBAs and other unskilled birth attendants may include provision of oral uterotonics $[71,72]$ and/or clean delivery kits [73] to mothers or postnatal home visits [74] to identify problems. TBAs' rootedness in the communities they serve and their upholding of sociocultural values and beliefs place them in good standing with the general population. Thus, despite the calls for modern medicine in pregnancy care, TBAs continue to be unabated and their practice continues to persist and even flourish in maternal health care in Zimbabwe.

\section{Conclusion}

The multifaceted crisis in Zimbabwe has destroyed the health sector, resulting in many Zimbabweans making use of alternative systems. Chikanda [75] highlights that the quality of care declined markedly due to nurses' outward migration in growing numbers. MMR has risen to record high levels and infant and under-5 mortality rates remain unacceptably high, with no signs of declining. In such a situation, reconsideration of women's maternal health is a policy imperative. Experts on reproductive health argue that for TBAs to help reduce infant and maternal mortality in countries south of the Sahara and other developing countries, there is need to equip skilled personnel with supplies to support carrying out basic preventive measures in obstetric care, anticipate and identify obstetric complications, administer nevirapine prophylaxis, and make appropriate and timely referrals backed up with efficient referral mechanisms [76]. This requires appropriate interventions that address barriers between rural mothers and formal health care system, including community educations which take into account the cultural values regarding reproductive health on all aspects of essential obstetric care and sensitizations of service providers to the situation of rural mothers [30, 71, 77].

Whilst increasing the proportion of births that take place with a skilled attendant is an internationally agreed health and development goal, shortage of skilled attendants persists throughout the developing world. Coverage by skilled attendants remains low in many countries because of the problems with availability, due to insufficient numbers of skilled attendants and inappropriate deployment of the existing personnel. However, studies show that the availability of SBAs at the institutional setup does not always guarantee accessing services and as a result home deliveries are still preferred by many. The person caring for a woman during labour and childbirth has greater influence than the place of delivery whether at home or in a health care facility [78].

Calls for midwives to learn specific skills from traditional birth attendants and elderly women have been made, rather than viewing modern medicine as superior to indigenous knowledge. A lack of understanding of cultural beliefs and practices results in a lack of support from the health system, thus contributing to delayed attendance of antenatal clinics and continued home birthing. It is against this background that I argue that because of their position of influence in society and their physical proximity to the pregnant women, TBAs are the first responders and hence the most critical resource in any maternal health intervention in the communities they live and work in. Therefore, there is still need for governments of poor resource countries to utilize them awaiting a better day.

The creation of dialogue, trustworthiness, patience, tolerance, willingness to collaborate, transparency, and familiarity during training are the keys when working with TBAs as partners in health care and sharing experiences. TBAs are the product of cultural system in community, and one of their roles is to protect culture from being invaded by other cultures [29, 30]. In Zimbabwe, TBAs have traditionally been assisting women during childbirth for centuries, providing community members with delivery services, pregnancy monitoring, emotional support, and practical assistance both before and after childbirth. These roles leave them in an intimate relationship with their service utilizers. TBAs are thus intricately woven into the maternal health and wellbeing of their clients. In this constrained fiscal environment, the key to a better future for Zimbabwe's women lies in focusing the resources on a few high impact interventions. In view of the factors obtaining on the ground in Zimbabwe, it is prudent to say that TBAs may prove a valuable resource to improve mother and newborn survival. However, to achieve their maximum involvement, there is a need to review the current child health program to give a suitable place to TBAs in the health care delivery system; integrate TBAs in newborn health programs; evolve an effective TBA training program; utilize the expertise and experience of TBAs in other community-based health delivery programs; and ensure that health centers and hospitals accept referrals from TBAs.

The social and cultural disposition of the TBA in the society is more lucrative than that of the health institution. Therefore, for cultural social and economic reasons, women consult TBAs for the monitoring of their pregnancy. Additionally, most TBAs are women and as a result women are relatively comfortable to consult them. Calling upon the services of the TBAs can go a long way in addressing both the physical and sociocultural barriers. Regarding physical barriers, TBAs live among the people that make use of their services and are available to the women for unlimited access. Because they live among the people and uphold the sociocultural beliefs that people value, they are more entrusted with the locals pregnancies with ease. Equipping TBAs with the skills needed to assist women with complications during childbirth 
can go a long way in ensuring the survival of the mother and newborn. Appropriate care during prenatal pregnancy, delivery and postnatal care are important for the health of both the mother and the baby. Long distance, high cost, and poor quality of care at the formal health facilities contribute to the decision to make use of TBAs. User fees, in particular, affect access to obstetric care, as hospital costs for EmOC costs are catastrophic.

\section{Recommendations}

(i) It is important to call upon the services of the TBAs as they can go a long way in addressing both the physical and sociocultural barriers in maternal health service provision.

(ii) There is a need to equip TBAs with the skills needed to assist women with complications during childbirth as this can go a long way in ensuring the survival of the mother and newborn. Appropriate care during prenatal pregnancy, delivery and postnatal care are important for the health of both the mother and the baby; thus, if the "preferred" TBAs are capacitated in terms of knowledge they can take better care of their clients ensuring the survival of both mother and child, especially given the incessant brain drain defining present day Zimbabwe.

(iii) User fees, in particular, need to be heavily subsidized or be removed altogether as they affect access to basic emergency obstetric care at hospitals.

(iv) Moreover, there is need for an increase in the coverage of EMOC and newborn facilities in terms of both quality and quantity including sufficient staff and relevant and functioning equipment.

(v) It is also important for midwives to learn specific skills from traditional birth attendants and elderly women rather than viewing modern medicine as superior to indigenous knowledge. This will go a long way in fostering trust and partnership between formal and alternative healthcare service providers.

(vi) There is need to reconsider the remuneration of SBAs with the aim of providing lucrative retention packages so that the country does not continue to incur training cost of personnel who then migrate and never get to serve in their country.

(vii) Overall, there is need for enabling policies and environment.

\section{Conflict of Interests}

The author declares that there is no conflict of interests regarding the publication of this paper.

\section{Endnotes}

1. Zimbabwe: More Midwifery Schools on the Cards by Sofia Mapuranga (The Standard March 52012 http://www.healthynewbornnetwork.org/press-release/ zimbabwe-more-midwifery-schools-cards). The Ministry of Health and Child Welfare says it will soon open three more midwifery training schools in the country to boost the human resource base in the sector and reduce maternal mortality rates. Speaking to senators on progress in the attainment of Millennium Development Goals (MDGs) 4 and 5 recently, ActingPermanent Secretary in the Ministry of Health and Child Welfare, Dr. Davies Dhlakama, said increasing the number of midwifery training schools would help reduce maternal deaths. "Expectations are that the ministry trains 700 more midwives yearly to curb the dwindled human resource base due to staff attrition and ensure that pregnant mothers receive effective care and treatment whenever they visit a health institution," he said. Dhlakama said the ministry had, through the department of reproductive health, implemented various lifesaving interventions aimed at reducing child mortality and improving maternal health. He said the shortage of midwives was a major challenge that contributed to the country's high maternal mortality rates. "Skilled attendance at delivery declined from $73 \%$ in 1999 to $68 \%$ in 2009, institutional delivery has remained constant at around $69 \%$ for the past decade, and home deliveries were $28 \%$ in 2007," said Dhlakama. "Midwives are marketable and their services are wanted everywhere. There is need to ensure that they are given enough incentives to motivate them if the country is to retain their services." The health ministry is also capacitating health workers through training to enable them to provide emergency obstetric and neonatal care as well as perform manual vacuum aspirations, implant insertions, and test for syphilis and cervical cancer. "More than 200 health workers have been trained since 2010 with at least two health workers per every secondary level health facility benefiting from this programme," he said. "A total of 67 midwives and doctors were trained in manual vacuum aspirations as provincial trainers and plans are underway to increase the number of trainees and procure more manual vacuum aspiration kits." A study conducted by the Ministry of Health and Child Welfare in 2007 established that $50 \%$ of maternal deaths were due to preventable factors such as delay in seeking health care, reaching care, and receiving effective treatment.

2. 2,000 New Midwives Trained, UNICEF 14/11/2013 http://www.newzimbabwe.com/news-13062-2,000+new + midwives+trained,+UNICEF/news.aspx. The United Nations Children's Fund and the Ministry of Health and Child Welfare have trained so far at least two thousand midwives as efforts to reduce high maternal deaths in the country scale-up. According to the latest Zimbabwe Demographic and Health Survey at least 10 women die every day as a result of pregnancy-related complications. In an interview on the side-lines of a recent media workshop on maternal and child health, UNICEF head of health and nutrition, Dr. Assaye Kassie, said midwives were extremely critical to reducing maternal 
deaths in Zimbabwe. "We refurbished and resuscitated the 21 midwifery training schools in the country. We have supported the midwifery schools to enroll more students. We have already produced 1000 midwives in 2012 and this year another 904 so we are left with another 1000," Kassie said. The program is a result of the Health Transition Fund (HTF), a multidonor pooled fund worth US $\$ 436$ million, supporting the implementation of key objectives and strategies outlined in the Zimbabwe Health Strategy (2009-2013) over the past five years. The HTF was launched in 2011 and is led by the health ministry. Kassie said more than \$114 million has been sourced to support the fund. "The total amount that we are looking for the whole HTF is about $\$ 400$ million" he said. "So, far we have received US $\$ 114 \mathrm{~m}$. We are hoping that the remaining will also be mobilised by the end of 2014 . We will be able to mobilize the additional resources for the health sector." The country's once vibrant health sector is now on a recovery path after a decade-long decline.

\section{References}

[1] B. T. Sparks, "A descriptive study of the changing roles and practices of traditional birth attendants in Zimbabwe," Journal of Nurse-Midwifery, vol. 35, no. 3, pp. 150-161, 1990.

[2] A. Bij de Vaate, R. Coleman, H. Manneh, and G. Walraven, "Knowledge, attitudes and practices of trained traditional birth attendants in the Gambia in the prevention, recognition and management of postpartum haemorrhage," Midwifery, vol. 18, no. 1, pp. 3-11, 2002.

[3] N. Goldman and D. A. Glei, "Evaluation of midwifery care: results from a survey in rural Guatemala," Social Science and Medicine, vol. 56, no. 4, pp. 685-700, 2003.

[4] G. Hansson, Mwana Ndimai: Toward an Understanding of Preparation for Motherhood and Childcare in the Transitional Mberengwa District, Zimbabwe, Uppsala University, Uppsala, Sweden, 1996.

[5] D. A. Diaz Ortiz, "We are all midwives," Midwifery Today, no. 80, 2006.

[6] R. Davis-Floyd, "Anthropological perspectives on global issues in midwifery," Midwifery Today, vol. 2002, pp. 1-12, 2002.

[7] S. L. Pigg, "Acronyms and effacement: traditional medical practitioners (TMP) in international health development," Social Science and Medicine, vol. 41, no. 1, pp. 47-68, 1995.

[8] S. L. Pigg, "Authority in translation. Finding, knowing, naming, and training 'traditional birth attendants"' in Childbirth and Authoritative Knowledge, Cross-Cultural Perspectives, Nepal, Ed., pp. 233-262, University of California Press, Berkley, Calif, USA, 1997.

[9] S. Anderson and F. Staugard, "Traditional midwives in Botswana: strengthening links between women," Health Policy and Planning, vol. 3, no. 1, pp. 40-47, 1988.

[10] UNFPA, State of World's Midwifery 2011: Delivering Health, Saving Lives, United Nations Population Fund, New York, NY, USA, 2011.

[11] Ministry of Health and Child Welfare, Traditional Midwives Training Guidelines, Government of Zimbabwe, Harare, Zimbabwe, 1997.
[12] World Health Organization, "Skilled birth attendants," WHO Fact Sheet WHO/MPS/08. 11, WHO, Geneva, Switzerland, 2008.

[13] World Health Organization, WHO Country Cooperation Strategy 2008-2013: Zimbabwe, WHO, Geneva, Switzerland, 2009.

[14] L. P. Freedman, W. J. Graham, E. Brazier et al., "Practical lessons from global safe motherhood initiatives: time for a new focus on implementation," The Lancet, vol. 370, no. 9595, pp. 1383-1391, 2007.

[15] S. S. Farooqi, Models of Skilled Attendance in Rural and Resource-Poor Settings: A Review of the Literature, Mujeres Enlazadas/Aliadas, Internship, 2009.

[16] UNICEF and UNFPA (United Nations Population Fund), Support to Traditional Birth Attendants. Evaluation Findings, vol. 7, Office of Oversight and Evaluation. United Nations Population Fund, New York, NY, USA, 2013.

[17] World Bank, Zimbabwe Data and Statistics, World Bank, 2011.

[18] V. Gonda, "Maternal Death Surge in Zimbabwe, Deputy Prime Minister Urges Action," 2012, http://m.voazimbabwe.com/a/ 1470263.html.

[19] Zimbabwe National Statistics Agency, Census 2012 National Report, 2012.

[20] TARSC and MoHCW, EquityWatch: Assessing Progress towards Equity in Health in Zimbabwe, EQUINET, Harare, Zimbabwe, 2011.

[21] T. Mathole, F. Majoko, G. Lindmark, and B. M. Ahlberg, "A qualitative study of women's perspectives of antenatal care in a rural area of Zimbabwe," Midwifery, vol. 20, no. 2, pp. 122-132, 2004.

[22] MoH, Zimbabwe National HIV and AIDS Estimates 2009, Ministry of Health, Harare, Zimbabwe, 2010.

[23] S. Crowe, M. Utley, A. Costello, and C. Pagel, "How many births in sub-Saharan Africa and South Asia will not be attended by a skilled birth attendant between 2011 and 2015?” BMC Pregnancy and Childbirth, vol. 12, article 4, 2012.

[24] WHO, "Maternal mortality," Fact Sheet 348, WHO, Geneva, Switzerland, 2012.

[25] Zimbabwe National Statistics Agency (ZIMSTAT) and ICF International, "Zimbabwe demographic and health survey 2010-2011,” Preliminary Report ZDHS 2010/11, 2010-2011.

[26] MoHCW (Ministry of Health and Child Welfare), Zimbabwe National HIV and AIDS Estimates 2003, MoHCW, Harare, Zimbabwe, 2003.

[27] G. L. Chavunduka, Traditional Medicine in Modern Zimbabwe, University of Zimbabwe Publications, Harare, Zimbabwe, 1994.

[28] L. M. Swantz, Religious and magical rites of Bantu women in Tanzania [M. Phil. thesis], University of Dar-es-Salaam, Dar es Salaam, Tanzania, 1966.

[29] S. Cosminsky, "Traditional midwifery and contraception," in Traditional Medicine and Health Care Coverage, R. H. Bannerman, J. Burton, and C. Wen-Chieh, Eds., World Health Organization, Geneva, Switzerland, 1983.

[30] E. J. Kayombo, “Traditional birth attendants (TBAs) and maternal health care in Tanzania," in Issues and Perspectives on Health Care in Contemporary Sub-Saharan Africa by Studies in Africa Health and Medicine, E. Kalipen and P. Thiuri, Eds., vol. 8, pp. 288-305, The Edwin Mellen Press, Lewston, NY, USA, 1997.

[31] MMEIG, UN Maternal Mortality Estimation Inter-agency Group, United Nations, 2010. 
[32] CSO and Macro, Zimbabwe Demographic and Health Survey 2005-2006, CSO and Macro International, Calverton, Md, USA, 2007.

[33] WHO/UNICEF/UNFPA and The World Bank, Maternal Mortality in 2005. Estimates Developed by WHO, UNICEF, UNFPA and the World Bank, World Health Organisation, Geneva, Switzerland, 2007.

[34] Central Statistical Office (Zimbabwe) and Macro International, Zimbabwe Demographic and Health Survey 1999, ZDHS 1999 \& 2005/6, Central Statistical Office and Macro International, Calverton, Md, USA, 2000.

[35] ZHWO (Zimbabwe Health Workforce Observatory), Human Resources for Health Country Profile, World Health Organization, Geneva, Switzerland, 2009, http://www.hrhobservatory.afro.who.int/images/Document_Centre/zimbabwe _hrh_country_profile.pdf.

[36] WHO, Global Observatory, World Health Organisation, Geneva, Switzerland, 2011.

[37] S. P. Munjanja, L. Nystrom, M. Nyandoro, and T. Magwali, Maternal and Perinatal Mortality Study, Ministry of Health and Child Welfare, Harare, Zimbabwe, 2007, http://www.unicef.org/ zimbabwe/ZMPMS_report.pdf.

[38] UNICEF, National Child Survival Startegy for Zimbabwe 20102015 Mapuranga 2012 is endnote 1, MoH, 2010.

[39] M. Maimbolwa, Maternity care in Zambia with special reference to social support [Ph.D. thesis], Department of Public Health Sciences, Global Health (IHCAR), Karolinska Institute, Stockholm, Sweden, 2005.

[40] M. Simpson-Hebert and S. L. Huffman, "The contraceptive effect of breastfeeding," Studies in Family Planning, vol. 12, no. 4, pp. 125-133, 1981.

[41] GoZ (Government of Zimbabwe), The National Health Strategy for Zimbabwe (2009-2013), Equity and Quality in Health: A People's Right, GoZ, 2010.

[42] O. Mudyarabikwa and A. Mbenga, "Distribution of public health sector workers in Zimbabwe: a challenge for equity in health," EQUINET Discussion Paper 34, EQUINET, Harare, Zimbabwe, 2006.

[43] MoHCW, An Analysis of Notified Institutional Maternal Deaths, January 2010-December 2011.

[44] M. Grieco and J. Turner, Maternal Mortality: Africa's Burden, Tookit on Gender, Transport and Maternal Mortality, World Bank, 2005.

[45] M. Hatem, J. Sandall, D. Devane, H. Soltani, and S. Gates, The Cochrane Review: Midwife-Led versus Other Models of Care for Childbearing Women (Review), The Cochrane Collaboration. John Wiley and Sons, 2009.

[46] G. Walraven and A. Weeks, "The role of (traditional) birth attendants with midwifery skills in the reduction of maternal mortality," Tropical Medicine and International Health, vol. 4, no. 8, pp. 527-529, 1999.

[47] S. Kruske and L. Barclay, "Effect of shifting policies on traditional birth attendant training," Journal of Midwifery \& Women's Health, vol. 49, pp. 306-311, 2004.

[48] I. T. Kamal, "The traditional birth attendant: a reality and a challenge," International Journal of Gynecology \& Obstetrics, vol. 63, supplement 1, pp. S43-S52, 1998.

[49] S. Saravanan, G. Turrell, H. Johnson, and J. Fraser, "Birthing practices of traditional birth attendants in South Asia in the context of training programmes," Journal of Health Management, vol. 12, no. 2, pp. 93-121, 2010.
[50] M. Islam, "Are skilled birth attendants really skilled?" Bulletin of the World Health Organisation, vol. 85, no. 10, p. 735, 2007.

[51] ACPD, Safe Motherhood: Women Need Skilled Birth Attendants, Action Canada for Population and Development, 2000-2009.

[52] Multiple Indicator Monitoring Survey (MIMS), Zimbabwe 2009, Zimstat and UNICEF, 2009.

[53] N. Gupta and M. R. Dal Poz, "Assessment of human resources for health using cross-national comparison of facility surveys in six countries," Human Resources for Health, vol. 7, article 82, 2009.

[54] MoHCW, The National Health Strategy for Zimbabwe (20092013), Equity and Quality in Health: A People's Right, MOHCW, 2009.

[55] C. Chimhete, "High fees drive patients away from hospitals. The Sunday Mirror," Harare, pp. 1-3, 2003.

[56] P. Nhindiri, S. Munjanja, I. Zhanda, G. Lindmark, and L. Nystrom, "A community-based study on utilisation of maternity services in rural Zimbabwe," African Journal of Health Sciences, vol. 3, no. 4, pp. 120-125, 1996.

[57] S. R. Fawcus, C. A. Crowther, P. van Baelen, and J. Marumahoko, "Booked and unbooked mothers delivering at Harare Maternity Hospital, Zimbabwe: a comparison maternal characteristics and foetal outcome," Central African Journal of Medicine, vol. 38, pp. 402-408, 1992.

[58] N. Chaudhury, H. Jeffrey, K. Michael, M. Kartik, and R. Halsey, Teachers and Healthcare Providers Absenteeism: A MultiCountry Study, MIMEO Development Research Group, World Bank, Geneva, Switzerland, 2003.

[59] R. Misra, R. Chatterjee, and S. Rao, India Health Report, Oxford University Press, New Dehli, India, 2003.

[60] B. Jordan, "High technology: the case of obstetrics," World Health Forum, vol. 8, pp. 312-319, 1987.

[61] S. Graham, Traditional birth attendants in Karamoja [Ph.D. thesis], South Bank University, Kampala, Uganda, 1999.

[62] UNICEF, Monitoring the Situation of Children and Women, UNICEF, New York, NY, USA, 2006, (Updated in November 2007).

[63] World Bank, Low-Income Countries Under Stress: Update, Operations Policy and Country Services, World Bank, Washington, DC, USA, 2005.

[64] Y. Chirwa, S. Witter, M. Munjoma et al., "The human resource implications of improving financial risk protection for mothers and newborns in Zimbabwe," BMC Health Services Research, vol. 13, article 197, 2013.

[65] A. Chimhowu, J. Manjengwa, and S. Feresu, Moving Forward in Zimbabwe: Reducing Poverty and Promoting Growth, Institute of Environmental Studies/Brooks World Poverty Institute (BWPI), Harare, Zimbabwe, 2010.

[66] Zimbabwe National Statistics Agency (ZIMSTAT), Quarterly Digest of Statistics 2013, ZIMSTAT, 2013.

[67] UNICEF, Situational Analyssis of the Status of Women and Children in Zimbabwe: A Call for Reducing Disparities and Improving Equity 2005-2010, UNICEF, CASS and GoZ, Harare, Zimbabwe, 2011.

[68] Ministry of Finance, Zimbabwe National Budget, 2013.

[69] E. Dzadecyson, Study on Maternal Mortality and Neonatal Morbidity in Africa, Rural Integrated Relief Services Ghana, 2007.

[70] Jamison, D. T. S. A. Shahid-Salles, J. Jamison, J. E. Lawn, and J. Zupan, "Incorporating deaths near time of birth into estimates 
of the global burden of disease," in Global Burden of Disease and Risk Factors, A. D. Lopez, C. D. Mathers, M. Ezzati, D. T. Jamison, and C. J. L. Murray, Eds., pp. 427-462, Oxford University Press, New York, NY, USA, 2006.

[71] M. Brennan, “Training TBAs reduces neonatal mortality and morbidity," Tropical Journal of Obsteterics and Gynaecology, vol. 1, pp. 44-47, 1988.

[72] N. Prata, P. Passano, T. Rowen, S. Bell, J. Walsh, and M. Potts, "Where there are (few) skilled birth attendants," Journal of Health Population and Nutrition, vol. 29, no. 2, pp. 81-91, 2011.

[73] S. Winani, S. Wood, P. Coffey, T. Chirwa, F. Mosha, and J. Changalucha, "Use of a clean delivery kit and factors associated with cord infection and puerperal sepsis in Mwanza, Tanzania," Journal of Midwifery and Woman's Health, vol. 52, no. 1, pp. 3743, 2007.

[74] A. T. Bang, H. M. Reddy, M. D. Deshmukh, S. B. Barkele, and R. A. Bang, "Neonatal and infant mortality in the ten years (19932003) of te Gadchirolli field trial: effect of homebased neonantal care," Journal of Perinatology, vol. 25, supplement 1, pp. S92S107, 2005.

[75] A. Chikanda, Emigration of medical doctors from Zimbabwe: migrant experiences, transnational linkages and prospects for diasporic engagement [Ph.D. thesis], University of Western Ontario, Ontario, Canada, 2010.

[76] H. Msaky, S. Kironde, J. Shuma, M. Nzima, V. Mlay, and A. Reeler, "Scaling the frontier: TBAs involvement on PMTCTservice delivery in Hai and Kilombero districts in Tanzania," in Proceedings of the International Conference on AIDS, pp. 11-16, Bangkok Thailand, July 2004.

[77] J. A. Safe, Ripoti Fupi Inayohusu Wakunga waJadi kwa Wizara ya Afya. Tanzania 1989.

[78] G. Kleiverda, A. M. Steen, I. Andersen, P. E. Treffers, and W. Everaerd, "Place of delivery in The Netherlands: maternal motives and background variables related to preferences for home or hospital confinement," European Journal of Obstetrics and Gynecology and Reproductive Biology, vol. 36, no. 1-2, pp. $1-9,1990$. 

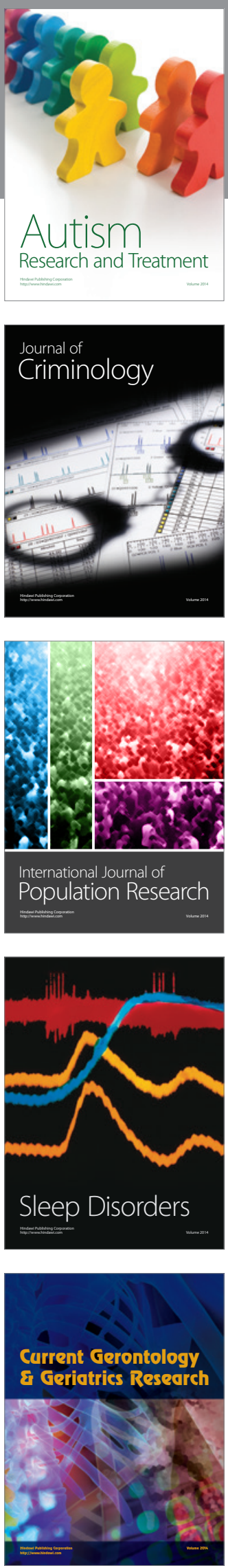
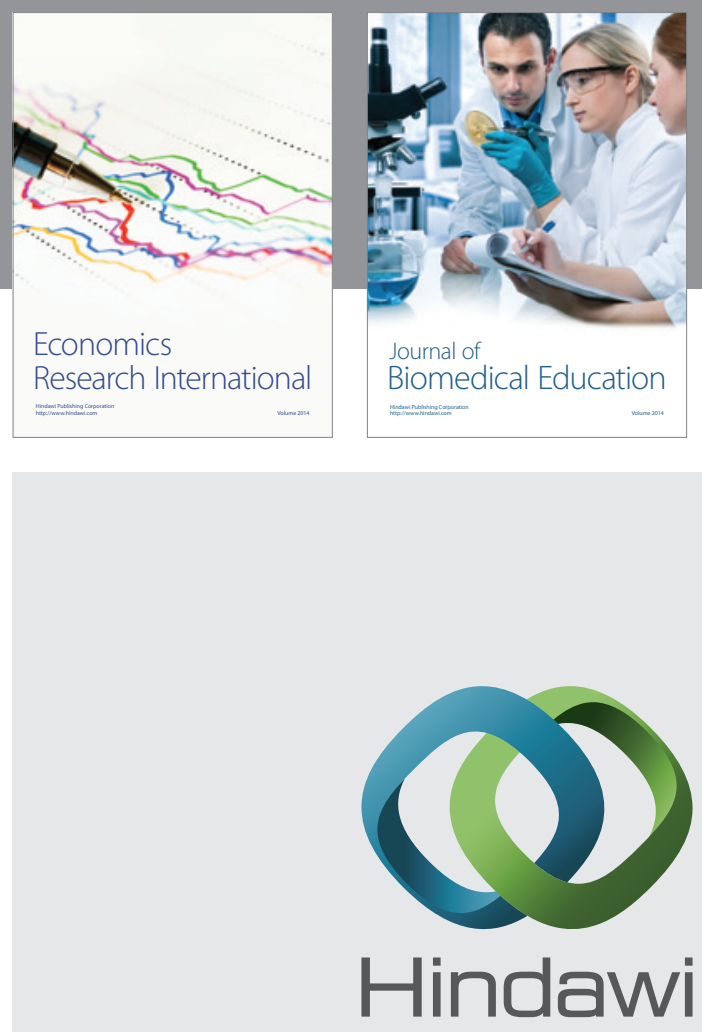

Submit your manuscripts at

http://www.hindawi.com
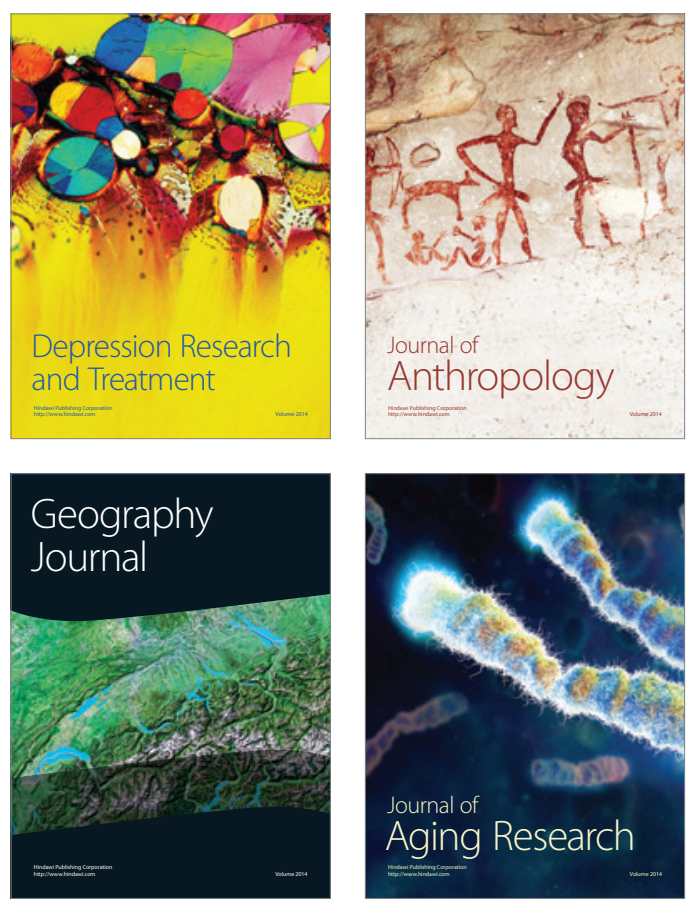
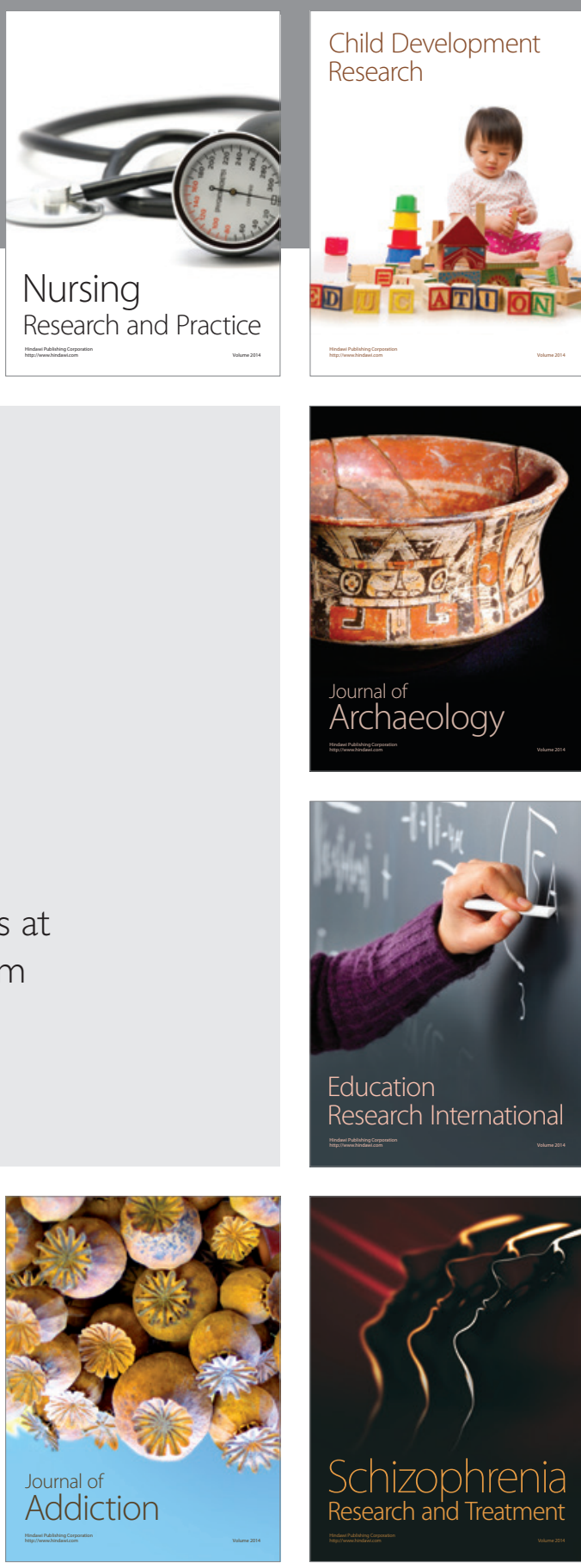

(D)
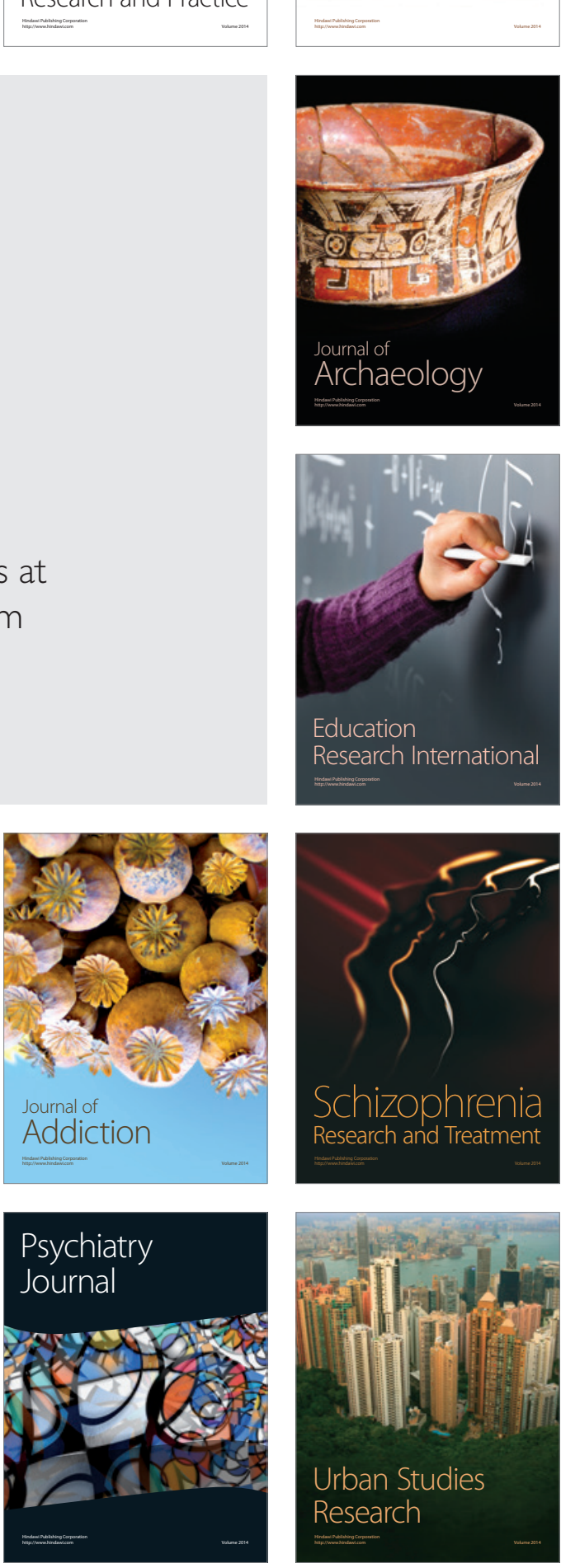